\title{
Geotecnologia aplicada ao agronegócio: conceitos, pesquisa e oferta
}

\author{
Miguelangelo Gianezini* \\ Rodrigo Saldias ${ }^{* *}$ \\ Alessandra Carla Ceolin ${ }^{* * *}$ \\ Fernanda Scharnberg Brandão ${ }^{* * * * *}$ \\ Eduardo Antunes Dias ${ }^{* * * * *}$ \\ Clandio Favarini Ruviaro ${ }^{* * * * * *}$
}

Resumo: A geotecnologia evoluiu significativamente nos últimos anos, motivada por interesses comerciais e legais, muitos dos quais ligados às atividades desenvolvidas no meio rural. Neste artigo, objetiva-se identificar os agentes pesquisadores, difusores, ofertantes e consumidores desta tecnologia aplicada ao agronegócio e analisar suas experiências e projeções. O estudo foi dividido em três etapas: i) visita a feiras do agronegócio, revisão de literatura e consulta a especialistas para construção do roteiro de entrevista; ii) aplicação do roteiro aos agentes pesquisadores, ofertantes e consumidores da geotecnologia; e iii) análise das informações e perspectivas fornecidas pelos entrevistados. Observou-se que a maioria das empresas opta pela contratação deste tipo de serviço como mecanismo de melhoria dos processos de gestão, na busca de um incremento da eficiência em seu planejamento, independentemente do setor no qual se encontram inseridas. A necessidade do cumprimento da legislação também influencia nesta decisão e impulsiona o desenvolvimento da própria tecnologia. Concluiu-se que a geotecnologia ainda pode ser aperfeiçoada, ajustando-se melhor às necessidades mencionadas pelos clientes, enquanto que as perspectivas vislumbradas pelos pesquisadores e ofertantes apontam para a democratização desta tecnologia, permitindo a melhora da eficiência e aumento do lucro a partir da gestão espacial.

Palavras-chave: Tecnologias emergentes; Geotecnologia; SIG; Agronegócio.

Classificação JEL: Q16; Q13; O32.

\footnotetext{
${ }^{n * *}$ Mestre em Ciências Sociais Aplicadas pela Universidade do Vale do Rio dos Sinos (UNISINOS). Doutorando em Agronegócios pela Universidade Federal do Rio Grande do Sul (UFRGS) e bolsista do CNPq. Endereço eletrônico: miguelgianezini@hotmail.com.

** Mestre em Agronegócios pela Universidade Federal do Rio Grande do Sul (UFRGS). Endereço eletrônico: rsaldias59@ hotmail.com.

*** Doutora em Agronegócios pela Universidade Federal do Rio Grande do Sul (UFRGS). Pós-doutoranda em Agronegócios pela Universidade Federal do Rio Grande do Sul (UFRGS). Endereço eletrônico: alessandra.acc@gmail.com.

***** Mestre em Agronegócios pela Universidade Federal do Rio Grande do Sul (UFRGS). Doutoranda em Agronegócios pela Universidade Federal do Rio Grande do Sul (UFRGS). Endereço eletrônico: ferbran@terra.com.br.

****** Doutor em Reprodução Animal pela Universidade de São Paulo (USP). Pós-doutorando em Agronegócios pela Universidade Federal do Rio Grande do Sul (UFRGS). Endereço eletrônico: eduardo.dias@ufrgs.br.

******* Mestre em Zootecnia pela Universidade Federal de Santa Maria (UFSM). Doutorando em Agronegócios pela Universidade Federal do Rio Grande do Sul (UFRGS). Endereço eletrônico: clandioruviaro@hotmail.com.
} 


\section{Introdução}

As feiras do agronegócio brasileiro são um importante espaço de comércio e de exposição de novas tecnologias e serviços. Nos últimos anos, vários estados brasileiros têm sediado importantes feiras agropecuárias e de equipamentos (Expointer, Techoshow, Feicorte, Agrishow e outras). Estes eventos concentram as novidades da moderna tecnologia agropecuária e agroindustrial, evidenciando o potencial do agronegócio brasileiro.

Uma destas novidades é a geotecnologia, que permite que a tecnologia de sistemas de informação geográficas auxilie os operadores do agronegócio, conferindo maior eficiência e precisão às suas atividades. Dentre seus múltiplos usos, a geotecnologia destaca-se pela possibilidade de leitura e análise a partir da coleta de informações sobre as características das propriedades e seus recursos, o que, antes do desenvolvimento da tecnologia da informática, era feito apenas em documentos e mapas em papel.

Neste artigo, são apresentados os conceitos e definições desta tecnologia, passando pela observação de sua oferta nas feiras do setor e usos aplicados ao agronegócio, até a análise da experiência e percepção dos pesquisadores, prestadores de serviço e clientes da mesma.

\section{Revisão bibliográfica}

As diversas tecnologias de tratamento e utilização de dados geográficos através de dados computacionais são definidas como geoprocessamento (Carvalho; Pina, 2000). De forma complementar, o processamento das diferentes informações de caráter geográfico como uso do solo, vegetação e expansão urbana são definidos como a técnica de geoprocessamento (Lahm, 2000).

A atual necessidade da visão sistêmica e da maior precisão e perfeição na tomada de decisões fazem com que a utilização da Geotecnologia tenha evoluído de forma significativa nos últimos anos. Neste contexto,

os Sistemas de Informações Geográficas (SIGs) permitem a realização de análises complexas ao integrar dados de diversas fontes e ao criar bancos de dados georreferenciados. Os SIGs tornam possível ainda a automatização da produção de documentos cartográficos. (Câmara; Medeiros, 1998, p. 3).

O avanço deste tipo de tecnologia mudou e influenciou atividades nas áreas de cartografia, análise e manejo de recursos naturais, tomada de decisão nas empresas agropecuárias e nas áreas relacionadas ao planejamento urbano e regional. São nestas questões relacionadas à tomada de decisão sobre problemas urbanos e ambientais que a geotecnologia apresenta um enorme potencial, principalmente se baseado em tecnologias de custo relativamente baixo, em que o conhecimento é adquirido localmente (Madruga, 2008).

Devido a sua ampla gama de aplicações, os SIGs incluem temas como agricultura, floresta, cartografia, cadastro urbano e redes de concessionárias 
(água, energia e telefonia) (Câmara; Medeiros, 1998). Neste sentido, destacamse três grandes maneiras de se utilizar os SIGs: como ferramenta para produção de mapas; como suporte para análise espacial de fenômenos; e como um banco de dados geográficos, com funções de armazenamento e recuperação da informação espacial.

Os SIGs são de extrema importância para a avaliação de terras para a agricultura. No que concerne ao agronegócio, os impactos provocados pelo modelo de agricultura predominante e o crescimento das exigências de sustentabilidade (social, ambiental e econômica) e de melhoria da qualidade dos produtos, constituem prioridades nas políticas de uso e de ocupação da terra. Desta forma, o uso dessa tecnologia revela-se como uma importante ferramenta no estudo de potencialidades espaciais e ambientais, uma vez que propicia o zoneamento de áreas de forma adequada e eficiente no que diz respeito aos aspectos como solos, clima, recursos hídricos, vegetação, entre outros.

Do ponto de vista da legislação brasileira ${ }^{1}$, o georreferenciamento possui maior destaque, em virtude da obrigatoriedade (que atinge a todos os proprietários rurais) da descrição do imóvel rural, em seus limites, características e confrontações, através de memorial descritivo. Ainda de acordo com a legislação, todos os imóveis rurais deverão ter seus perímetros descritos, com coordenadas integradas ao Sistema Geodésico Brasileiro, conferindo maior segurança aos proprietários rurais no que tange à descrição e área de seu imóvel, uma vez que a coordenada geodésica, depois de certificada pelo INCRA, é única em todo o país. Caso isso não se cumpra, pode haver impedimento da efetivação do registro, em qualquer situação de transferência do imóvel rural.

\section{Metodologia}

Na primeira fase da pesquisa para este artigo, procurou-se estabelecer um limite para a busca de informações, com visitas a feiras e eventos do setor agronegocial, revisão de literatura e consulta a especialistas para construção do roteiro de entrevista.

Com isso, optou-se por uma amostra intencional ou de seleção intencional, uma vez que se seguiu uma estratégia definida com os elementos da amostra previamente escolhidos. Depois da abordagem feita na empresa prestadora de serviços de geotecnologia, escolheu-se um grupo de interesse do qual foram obtidas as informações.

$\mathrm{Na}$ segunda fase da pesquisa aplicou-se o roteiro de entrevistas aos principais agentes pesquisadores, ofertantes e consumidores da geotecnologia, previamente selecionados (ver Quadro 1) considerando os elementos de proximidade (estado do Rio Grande do Sul) e tempo para a realização da pesquisa.

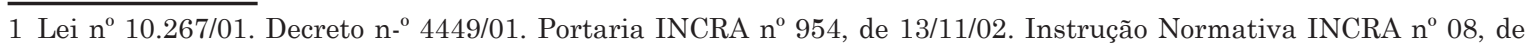
13/11/02. Instrução Normativa INCRA n ${ }^{\circ}$ 13, de 17/11/03. 
Quadro 1 - Agentes entrevistados, setordeatividade e natureza

\begin{tabular}{|l|l|}
\hline \multicolumn{1}{|c|}{ Agentes } & \multicolumn{1}{c|}{ Setor - Natureza } \\
\hline $\begin{array}{l}\text { UFRGS Projeto GeoSafras } \\
\text { - Conab. }\end{array}$ & Pesquisa em Geotecnologia, Agrometeorologia Pública \\
\hline Brasgeo & $\begin{array}{l}\text { Oferta de serviço utilizando ferramentas de Geoinformação } \\
\text { Privada }\end{array}$ \\
\hline Clientes (Brasgeo) & Petroquímica, Florestal, Moinhos. \\
\hline
\end{tabular}

Fonte: Elaboração própria.

Ressalta-se que este tipo de amostra não é representativo do universo, tornando-se, portanto, impossível a generalização dos resultados da pesquisa à população. Porém, para os objetivos deste artigo, este tipo de metodologia permitiu analisar as realidades de diferentes agentes envolvidos com a utilização deste tipo de tecnologia vinculada ao agronegócio.

Assim, na última fase foram analisadas as informações, opiniões e perspectivas fornecidas pelos entrevistados.

\section{Resultados e discussão}

\subsection{Agentes de pesquisa - GeoSafras}

A partir das informações fornecidas pelos entrevistados, observa-se que a importância da iniciativa do projeto GeoSafras reside no fato de que o mesmo fornecia para a Conab informações, dados e resultados de domínio público que permitiram o desenvolvimento de políticas a partir de uma visão ampla da realidade produtiva da agricultura brasileira.

O GeoSafras faz uso de geotecnologias como o sensoriamento remoto, GPS (Global Positioning System) e Sistemas de Informações Geográficas no mapeamento e monitoramento das culturas, de aplicação de modelos agrometeorológicos nos prognósticos de rendimento diante das condições climáticas nos períodos cruciais do desenvolvimento da planta e ainda de levantamentos de dados de campo como apoio nas estimativas de área e de produtividade (Figueiredo, 2005). Desde sua criação, a atuação do GeoSafras situa-se em três áreas principais: a previsão de safras, o georreferenciamento e o sensoriamento remoto.

Assim, o projeto trabalha com o monitoramento das culturas (usando análises agrometeorológicas e de índices vegetais), assim como estimativas de área através de satélites de média resolução e estimativas de rendimento. Nos últimos anos, contudo, a relação com a Conab sofreu algumas alterações e o projeto perdeu autonomia, passando a atuar sob demandas específicas e não mais como um ofertante de informação e tecnologia

\subsection{Agentes ofertantes}

Dentre os agentes pesquisados, foi escolhida para análise a empresa Brasgeo como um dos exemplos da iniciativa privada que oferta produtos e serviços 
a partir do uso da geotecnologia. A prestação de serviços realiza-se nas zonas urbana e rural. Na primeira, as atividades principais envolvem a atualização cadastral e na segunda, as atividades relacionam-se com a regulamentação fundiária conforme a legislação vigente, a certificação, o mapeamento para tomada de decisão e a gestão ambiental.

Além disso, os serviços oferecidos aos operadores do agronegócio possibilitam a assistência ao planejamento rural mediante o monitoramento de lavouras, custos e análises logísticos nas propriedades rurais. Também se utilizam este tipo de tecnologias para análises de potenciais produtivos e compra e venda de propriedades rurais, assim como para gerar uma base cartográfica para as empresas que trabalham com rastreabilidade.

Atualmente, a empresa é responsável por mais de 30\% dos imóveis rurais georreferenciados no Rio Grande do Sul. Analisando as informações, considera-se que a atuação de empresas prestadoras de serviços como esta é possível a partir de parcerias com outras empresas que proporcionam soluções em geoinformação com eficiência e garantia do atendimento às necessidades dos clientes.

\subsection{Agentes contratantes}

Para analisar as informações coletadas junto aos clientes das empresas que prestam serviços de geoinformação, optou-se por agrupar as questões em seis momentos de análise.

No primeiro, estão agrupadas as motivações que levaram as empresas a contratar este tipo de serviço, incluindo o contato com a tecnologia e em quais atividades a mesma é utilizada. Como motivações é possível destacar: as exigências quanto à regulamentação legal; necessidades de gestão para atividades voltadas para o agronegócio; e melhorias na gestão estratégica e planejamento técnico da empresa. As áreas de utilização da tecnologia são: mapeamento, planejamento florestal, avaliação de terras, planos de manejo, orçamentos, políticas de legislação do uso da terra, conservação de recursos ambientais e melhorias de monitoramento de informações georreferenciais. Observou-se que a maioria das empresas entrevistadas opta pela contratação deste tipo de serviços como mecanismo de melhoria dos processos de gestão, na busca de um incremento da eficiência no planejamento das empresas, independentemente do setor no qual elas encontram-se inseridas. Outro elemento que influencia na decisão da contratação, ou acelera o processo, é a necessidade do cumprimento da legislação, que passa da simples regularização de áreas até as questões de impacto ambiental.

No segundo momento de análise está representado o grau de atendimento às necessidades na percepção dos clientes desta tecnologia. Nesta análise, a maioria (60\%) indica necessitar de ajustes à tecnologia. Os resultados permitem identificar que a geotecnologia ainda pode ser aperfeiçoada, ajustando-se melhor às necessidades apontadas pelos clientes entrevistados. Foram apontadas questões como a classificação de sítios e manejos específicos para cada um, a 
aquisição de softwares e o treinamento de equipes.

No terceiro momento, estão expostas as vantagens e desvantagens observadas pelos clientes desta tecnologia no que se refere à gestão dos negócios e tomadas de decisão das empresas.

Quadro 2 - Vantagens e desvantagens do uso da geotecnologia

\begin{tabular}{|l|l|}
\hline \multicolumn{1}{|c|}{ Vantagens do uso SIGs } & \multicolumn{1}{c|}{ Desvantagens do uso SIGs } \\
\hline $\begin{array}{l}\text { Fornecem uma base real e confiável para } \\
\text { avaliação do imóvel }\end{array}$ & Alto custo \\
\hline $\begin{array}{l}\text { As imagens de satélite podem ser utilizadas } \\
\text { como provas jurídicas e legais para efeitos de } \\
\text { regularização de propriedades }\end{array}$ & Necessidade de conhecimento especializado \\
\hline $\begin{array}{l}\text { Melhorias na gestão estratégica e } \\
\text { planejamento técnico da empresa }\end{array}$ & $\begin{array}{l}\text { Trabalho de conferência de campo dos dados } \\
\text { coletados a fim de verificar a confiabilidade } \\
\text { dos mesmos }\end{array}$ \\
\hline
\end{tabular}

Fonte: Elaboração própria.

A análise das informações guarda similaridades com o que foi exposto no primeiro momento, acrescentando aqui a questão da confiabilidade das informações como uma das vantagens para a contratação deste tipo de serviços. Mas também revela, como principais desvantagens, a percepção do alto custo ainda existente e a necessidade de conhecimento especializado que esta tecnologia requer.

No quarto momento, analisa-se a percepção das empresas sobre a representatividade dos custos da utilização dos SIGs. Aqui se percebeu que muitos dos entrevistados que mencionam o alto custo da tecnologia ainda não conseguem quantificar com precisão quanto isto representa nos custos de sua empresa. A maioria dos entrevistados também não soube avaliar exatamente o tempo estimado de retorno do investimento nesta tecnologia. Neste sentido, os clientes desconhecem os percentuais do aumento da sua receita e ou a diminuição dos custos envolvidos a partir do uso da tecnologia dos SIGs.

No quinto momento, foram reunidas as opiniões das empresas sobre as necessidades de capacitação para contratar e aproveitar as possibilidades do uso desta tecnologia na melhoria da gestão. Aqui, se observou que: a) há necessidade de capacitação para as pessoas que vão interpretar e manejar os resultados fornecidos pela prestadora de serviço; b) é importante conhecer a ferramenta ainda antes da contratação, suas possibilidades de uso e alternativas; e c) é importante saber quais são os requerimentos reais que a empresa tem para que então a tecnologia seja estruturada em cima destas necessidades.

Por fim, no sexto momento analisam-se as perspectivas futuras de desenvolvimento e uso desta tecnologia, mencionadas pelos agentes entrevistados nesta pesquisa. Os clientes apontam a necessidade de atendimento a questões pontuais que vão desde o planejamento de extração, plantio e logística, passando pelo acompanhamento dos rendimentos, até a consolidação da tecnologia existente. Os representantes da empresa ofertante da tecnologia assinalam tendências, que perpassam pelo foco na figura do cliente "empresário rural" e nas empresas que investem no agronegócio. Acreditam que com a tecnologia, seus clientes conseguirão reduzir custos, realizar planejamento por unidade, 
melhorando assim sua eficiência e aumentando o lucro a partir da "gestão espacial". Além disto, há cada vez menos necessidade da presença do gestor in loco. Entendem, ainda, que os custos da contratação da tecnologia vêm diminuindo e apontam como resultado, as cooperativas enquanto clientes que podem utilizá-la para diminuir os custos dos cooperados. Finalmente, os pesquisadores do projeto GeoSafras preveem a democratização desta tecnologia e analisam que os usos da mesma é que farão a diferença no futuro, sendo que suas possibilidades não terão limites, considerando que hoje o acesso é livre, tornando possível o que antes era inviável.

\section{Conclusão}

Constatou-se que experiências pioneiras como a do projeto GeoSafras demonstram o potencial das entidades públicas e seu papel na pesquisa e desenvolvimento de tecnologia e na disponibilização dos dados em escala macro, subsidiando futuras pesquisas e políticas governamentais. Também percebeuse que as atividades da iniciativa privada indicam uma tendência crescente de oferta da geotecnologia direcionada para o empresário rural, mas que ainda reside no atendimento de grandes empresas, em escala micro, no intuito de reduzir custos, buscando realizar planejamento por unidade, melhorando a eficiência e aumentando o lucro a partir da "gestão espacial".

Avaliou-se que os clientes consideram a tecnologia uma importante ferramenta para suas atividades na busca de maior eficiência em seu planejamento e cumprimento da legislação, contribuindo assim no desenvolvimento da própria tecnologia. Apesar disto, a geotecnologia ainda pode ser aperfeiçoada, ajustandose melhor às necessidades mencionadas.

Por fim, conclui-se que as perspectivas vislumbradas pelos pesquisadores e ofertantes apontam para a democratização desta tecnologia, permitindo o incremento da eficiência e melhorando os resultados econômicos e ambientais a partir deste tipo de gestão. Para o agronegócio, a importância da tecnologia de sistemas de informação geográfica não reside apenas na sua existência, mas sim no uso que se fará dela nos próximos anos.

\section{Referências}

BRASGEO - Mapeamento e consultoria - Soluções em Geoinformação. (2011). URL [on-line]: http://www.brasgeo.com. Acesso em: 7 de setembro de 2011.

Câmara, G.; Medeiros, J. S. de. (1998). "Princípios básicos em geoprocessamento". In Assad, E. D.; Sano, E. E. Sistema de informações geográficas: aplicações na agricultura. Brasília: Embrapa.

Carvalho, M. S.; Pina, M. F. (2000). Conceitos básicos de sistemas de informação geográfica e cartografia aplicados à saúde. Brasília: Organização Panamericana de Saúde. 
Figueiredo, D. C. (2005). "Projeto GeoSafras - aperfeiçoamento do sistema de previsão de safras da CONAB". URL [on-line]: http://www.agencia.cnptia.embrapa.br/ Repositorio/projetogeosafras_000fxgfvhfo02wyiv80soht9hgzrunmj.pdf. Acesso em: 14 de outubro de 2011.

Lahm, R. A. (2000). "Noções básicas de sensoriamento remoto e geoprocessamento". In Verdum, R.; Strohaecker, T. (Org.) (2000). Desenvolvimento regional, turismo e educação ambiental. Porto Alegre: Associação dos Geógrafos Brasileiros.

Madruga, R. A. (2008). Geração de base cartográfica digital utilizando imagens de satélite de altíssima resolução espacial para suporte ao planejamento rural. Porto Alegre: dissertação de Mestrado em Sensoriamento Remoto, Universidade Federal do Rio Grande do Sul. 